\title{
Processos de subjetivação e territórios de vida: o trabalho de transição do hospital psiquiátrico para serviços residenciais terapêuticos
}

I 1 Felipe Wachs, ${ }^{2}$ Camila Jardim,

${ }^{3}$ Simone Maineri Paulon, ${ }^{4}$ Vera Resende I

Resumo: O artigo discute o cuidado em saúde mental no contexto da Reforma Psiquiátrica em implementação no Brasil. Resulta de uma proposta de pesquisa-intervenção potencializadora da desinstitucionalização de moradores do Hospital Psiquiátrico São Pedro e aborda, mais precisamente, o trabalho de transição para os serviços residenciais terapêuticos Morada São Pedro, na cidade de Porto Alegre. Para além de mero deslocamento de um espaço físico para outro, a concepção de transição trabalhada diz respeito mais à apropriação de novos territórios subjetivos e de formas outras de viver e habitar. Os processos de subjetivação que emergiram entre usuários, trabalhadores e em nós pesquisadores, ao transitar por novos territórios de vida, foram tomados como dispositivos analisadores e são aqui problematizados, a fim de refletir sobre a função que a transição possa ter na produção de vida desses novos integrantes da vida urbana.

> Palavras-chave: saúde mental; desinstitucionalização; serviços de saúde mental; processos de subjetivação; acompanhamento terapêutico.

\author{
1 Professor de Educação Física, \\ especialista em Saúde Mental \\ Coletiva, mestre em Ciências \\ do Movimento Humano \\ (UFRGS); professor substituto/ \\ UFRGS. Endereço eletrônico: \\ felipewachs@gmail.com \\ 2 Psicóloga, especialista \\ em Saúde Mental Coletiva. \\ Endereço eletrônico: \\ camilajardim@gmail.com \\ ${ }^{3}$ Psicóloga, doutora em \\ Psicologia Clínica (PUC-SP); \\ docente e pesquisadora do \\ Instituto de Psicologia/UFRGS; \\ docente do PPG em Psicologia \\ Clínica e Institucional/UFRGS. \\ Endereço eletrônico: simone. \\ paulon@ufrgs.br \\ ${ }^{4}$ Professora de Educação Física, \\ sanitarista. Endereço eletrônico \\ veramorada@gmail.com
}

Recebido em: 08/07/2009. Aprovado em: 25/02/2010. 


\section{Adentrar novas moradas}

A Reforma Psiquiátrica que vem sendo implementada no Brasil propõe a progressiva substituição de um modelo de cuidado em saúde mental centrado em hospitais psiquiátricos por uma rede de serviços de saúde que potencialize o convívio social dos usuários. Àqueles que moram em hospitais psiquiátricos são destinadas políticas específicas de desinstitucionalização.

No Rio Grande do Sul, a Lei 9.716, de 07 de agosto de 1992, determina a "substituição progressiva dos leitos nos hospitais psiquiátricos por uma rede de atenção integral em saúde mental” (BRASIL, 2004a, p. 63). A referida Lei prevê ainda:

Aos pacientes asilares, assim entendidos aqueles que perderam o vínculo com a sociedade familiar, e que se encontram ao desamparo e dependendo do Estado para sua manutenção, este providenciará a atenção integral, devendo, sempre que possível, integrá-los à sociedade através de políticas comuns com a comunidade de sua proveniência (BRASIL, 2004a, p. 66).

A Lei Federal 10.216/2001 determina que "o paciente há longo tempo hospitalizado ou para o qual se caracterize situação de grave dependência institucional, decorrente de seu quadro clínico ou de ausência de suporte social, será objeto de política específica de alta planejada e reabilitação psicossocial assistida [...]" (BRASIL, 2004a, p.18).

Entre as políticas para desinstitucionalização de moradores de hospitais psiquiátricos, está a criação de Serviços Residenciais Terapêuticos ${ }^{1}$ (SRT) introduzidos no âmbito do Sistema Único de Saúde (SUS) através da Portaria nº6/2000. O SRT é uma importante estratégia para garantir o princípio da desinstitucionalização ${ }^{2}$ proposto pela Reforma Psiquiátrica. Ele oferece um modo de habitar que investe nas potências dos portadores de sofrimento psíquico, aposta na sua convivência urbana e busca concretizar o fim dos manicômios. Em dados recentes do Ministério da Saúde (BRASIL, 2006), o número de SRTs cadastrados, que em 2002 eram 85, alcançou 475 ao final de 2006.

Outra importante política criada é o Programa "De Volta Para Casa" (BRASIL, 2003), que institui o auxílio-reabilitação psicossocial através da Lei 10.708, de 31 de julho de 2003. Tal benefício contribui para a manutenção financeira dos usuários, necessidade concreta para habitar a cidade sem a "provisão caridosa institucional" do hospital psiquiátrico. 
Para que as mudanças no cuidado não sejam apenas um aborto institucional, consideramos importante discutir e humanizar o processo de transição. O presente artigo $^{3}$ é fruto de um projeto de pesquisa-intervenção potencializador da transição de moradores do Hospital Psiquiátrico São Pedro (HPSP) para os Serviços Residenciais Terapêuticos Morada São Pedro (Morada), ambos sob gestão da Secretaria Estadual de Saúde do Rio Grande do Sul e localizados na cidade de Porto Alegre.

O Morada é parte de um projeto maior denominado "São Pedro Cidadão", que envolve, entre outras atividades, oficinas de geração de renda e a construção de SRTs. Atualmente, o Morada é constituído por 27 casas, que podem ser ocupadas por até quatro usuários. São caracterizados como SRTs do "tipo I" (BRASIL, 2004b), nos quais os cuidadores não permanecem $24 \mathrm{~h} /$ dia, e estão voltados para inserção dos moradores na rede social existente. $\mathrm{O}$ acompanhamento em cada residência é realizado diurnamente por um profissional de referência, que desenvolve sua intervenção a partir da construção, junto com o usuário, de um plano terapêutico individualizado.

Ao propormos, em meados de 2004, a realização da pesquisa-intervenção ${ }^{4}$ aqui relatada, havia mais de um ano que não ocorria a transferência de qualquer morador do HPSP para o Morada. Na condição de alunos ou orientadores associados às atividades da Residência Integrada em Saúde com ênfase em Saúde Mental Coletiva, constituímos uma frente de trabalho junto à equipe do Morada para reavivar o processo de altas e apoiar a transferência dos asilados para o equipamento da rede de saúde criado recentemente (JARDIM; WACHS; GOMES, 2005). Os residentes envolvidos nesta atividade passaram a ser denominados de "equipe de transição" e desenvolviam suas atividades em três frentes de intervençôes: uma voltada para os trabalhadores dos serviços; a segunda junto aos moradores que já residem no Morada; e a terceira, voltada para os moradores que ainda estão no HPSP e têm desejo de morar no SRT. Através delas, procuramos refletir acerca dos processos de subjetivação de usuários, que passam a conviver em territórios ${ }^{5}$ para além do manicômio; dos processos de subjetivação de trabalhadores, que precisam construir novos territórios de cuidado e romper com a lógica tutelar; dos nossos próprios processos de subjetivação produzidos no trânsito pelo território dos Residenciais Terapêuticos no decorrer da pesquisa. A discussão que passamos a apresentar foi norteada pelos dispositivos analisadores que emergiram ao longo do processo de 
investigação/intervenção. Os dispositivos analisadores são "acontecimentos - no sentido daquilo que produz rupturas, que catalisa fluxos, que produz análise, que decompõem" (PASSOS; BARROS, 2000, p. 73).

\section{Traçar itinerários}

A estruturação e desenvolvimento do trabalho parte dos objetivos de discutir, humanizar e efetivar a transição de moradores do hospital para um SRT e sustenta-se na referência metodológica da pesquisa-intervenção (PASSOS; BARROS, 2000; ROCHA; AGUIAR, 2003; PAULON, 2005). Esta tem como base uma "arguição que desmancha territórios constituídos e convoca a criação de outras instituiçōes, onde o que interessa são os 'movimentos', as 'metamorfoses', não definidas a partir de ponto de origem e um alvo a ser atingido, mas como processo de diferenciação" (PASSOS, BARROS, 2000, p. 73).

A pesquisa foi estruturada nas três frentes de intervenção antes descritas, que incluíram estratégias de trabalho diferenciadas, a saber:

- A primeira frente de intervenção, junto aos trabalhadores do SRT, realizou-se nos espaços de reunião de equipe, grupos de estudos/reflexão e seminários. Nas reuniōes de equipe, trazíamos como pauta frequente os acontecimentos relativos ao trabalho da transição, como uma estratégia de produzir na equipe reflexões acerca dos processos aí envolvidos, bem como promover o conhecimento inicial acerca dos moradores com os quais estariam trabalhando futuramente. Isso, de alguma forma, já agia como um disparador da vinculação entre usuários em transição e equipe do Morada. Nos grupos de estudos e reflexão, buscamos construir junto com os trabalhadores um suporte teóricotécnico para sustentar as práticas cotidianas, principalmente as relacionadas aos impasses e dificuldades advindos do trabalho de transição. Dois grandes seminários foram propostos como momentos de parada da equipe com caráter avaliativo-propositivo do trabalho que a todos envolvia tão intensamente.

- Com os moradores que já residiam no SRT, foram realizadas assembleias que reuniam grande parte deles para discutir o funcionamento do serviço e aventar estratégias para ampliar sua forma de relação tanto com o próprio SRT como com a comunidade vizinha e com a cidade.

- A terceira frente da pesquisa-intervenção, que constitui o foco do presente artigo, foi a dos "usuários em transição". O processo de escolha de quais mo- 
radores do HPSP seriam público-alvo do projeto se deu a partir da circulação dos residentes/pesquisadores por unidades asilares do hospital. A presença nas unidades foi, aos poucos, mobilizando alguns moradores que - ao saberem dos motivos pelos quais os residentes/pesquisadores estavam ali - aproximavam-se ou distanciavam-se dos mesmos. Entre os que se aproximaram, foram selecionados para transição aqueles que receberam aval das equipes de suas unidades no hospital. Durante o período da pesquisa, participaram das atividades de transição 19 usuários, dos quais oito concretizaram sua mudança para o SRT.

A escolha pela pesquisa-intervenção aconteceu a partir das trajetórias teóricas dos autores em negociação com aquilo que se apresentava nas discussões com a equipe, frente às demandas do campo. Uma das ferramentas utilizadas, dentro do arcabouço teórico-metodológico da pesquisa-intervenção, junto aos usuários em transição do HPSP para o SRT, foi o Acompanhamento Terapêutico, ${ }^{6}$ compreendido como

[...] uma modalidade clínica que se utiliza do espaço público da cultura como dispositivo para o ato terapêutico. $\mathrm{O}$ trabalhador de saúde que se utiliza dele na sua prática circula com o usuário pelo tecido social, facilitando a emergência de um encontro. Ele torna-se, assim, testemunha do processo de criação desencadeado, criando outros espaços possíveis para o dito "louco" na cidade (CABRAL; BELLOC, 2004, p. 115).

Através das ferramentas/dispositivos ofertadas nesta abordagem, procuramos proporcionar uma escuta e um acompanhamento que possibilitassem a construção de uma ponte para travessia do modo de vida manicomial para um projeto de vida no residencial terapêutico e, ao mesmo tempo, permitissem atentar para acontecimentos que se constituiriam como dispositivos analisadores no desenvolvimento da pesquisa. Iniciamos as atividades de transição junto aos moradores do hospital com acompanhamentos, ora individuais, ora coletivos. Entre o estar nas unidades, caminhadas pela vizinhança do hospital e visitas a conhecidos no Morada, houve uma aproximação que potencializou o estabelecimento de vínculo entre moradores e pesquisadores. Através dele, e calçado nele, foram se abrindo "brechas" entre o modo de subjetivação manicomial e outros territórios de vida.

Timidamente, iniciaram-se algumas saídas pela cidade (que foram se intensificando) em espaços escolhidos pelos moradores que, algumas vezes, envolviam a compra de roupas, idas ao supermercado, cinema, banco. Com o 
andar do processo de transição, tornou-se necessário o restabelecimento de uma "Casa de Passagem". Os apartamentos e a casa de passagem utilizados no início do projeto "São Pedro Cidadão" haviam sido desativados. Utilizamos um dos SRTs ainda desocupados no Morada, para que moradores do hospital pudessem experimentar o viver numa casa antes de efetivar uma mudança definitiva. Nesse espaço, passaram a ser desenvolvidos almoços, cafés da tarde, roda de chimarrão, pernoites, atividades de cuidado com a casa. É importante destacar que tais atividades não se restringiram a um "treino de habilidades", mas se constituíram como fundamentais para a apropriação de novos territórios de vida. Após a mudança efetiva dos moradores do hospital em acompanhamento, a equipe de transição compartilhou, durante determinado período, o papel de técnico de referência dos novos usuários com algum membro da equipe fixa do Morada.

O corpus da pesquisa foi constituído predominantemente por diários de campo, mas também por registros feitos através de fotos, filmagens, desenhos e textos escritos. $\mathrm{O}$ tratamento dos dados obtidos na pesquisa foi realizado a partir de dispositivos analisadores e da análise de implicação. A análise de implicação tem como princípio norteador que a aproximação com o campo inclui, sempre, "a permanente análise do impacto que as cenas vividas/observadas têm sobre a história do pesquisador e sobre o sistema de poder que legitima o instituído, incluindo aí o próprio lugar de saber e estatuto de poder do 'perito pesquisador"” (PAULON, 2005, p. 23). Contribuíram para esse processo de análise: a supervisão de campo realizada pela chefia do SRT, a supervisão teórico metodológica e a constante reflexão/avaliação que o trabalho realizado em dupla proporcionou.

Três acontecimentos produzidos no processo de transitar e na constituição dos novos territórios merecem ser destacados, pelo que anunciam dos conteúdos de processos de subjetivação dos usuários do SRT com quem trabalhamos durante a pesquisa-intervenção, constituindo, assim, dispositivos analisadores.

\section{Transitar novos territórios}

O casal Amélia e Jorge tinha programado passar um fim de semana na Casa de Passagem do Morada. No caminho do Hospital para o Morada, foram questionados sobre o que fariam lá durante $O$ periodo em que estariam experimentando o residir em uma casa. A resposta foi imediata: "cozinhar, limpar a casa, tomar chimarrão...". 
A resposta dada pelo casal é resposta comum entre os moradores do hospital que participavam de atividades na Casa de Passagem. Permanece na concepção dos funcionários que trabalham com moradores no hospital um perfil idealizado de quem poderia estar habitando uma casa: aquele que dá conta sozinho de cozinhar, limpar, lavar, cuidar de si e do espaço de moradia. A resposta do casal vem ao encontro disso que é esperado. Ao mesmo tempo em que apresenta aquilo que o outro deseja ouvir, apresenta, também, uma marca de potência: "eu quero, eu posso, eu tenho condições de morar numa casa". A autonomia na realização das atividades de vida diária (AVDs), juntamente com o desejo de sair do hospital e a condição de beneficiário de recursos financeiros, foram os critérios adotados em 1999 quando fundada a primeira "Casa de Passagem". Contudo, tais critérios se mostraram muito restritivos, excluindo quase todos pacientes, pela dificuldade em reunir todos os requisitos exigidos (PAULON et al., 2007, p. 125). A perspectiva de trabalho que identificamos como mais adequada - em relação à transição dos asilados para o Morada - não é a de avaliar a capacidade de autonomia dos moradores na realização de todas as atividades domésticas. Tal critério se mostrara excludente para que muitos avançassem no processo de desinstitucionalização. Consideramos o desejo do morador como critério determinante para o processo de transição. Trabalhamos na lógica de que o fundamental seria ele se sentir em condições de bancar uma mudança na vida.

Esse processo de elaboração de uma escolha, formulação do desejo, é diferente para cada um: alguns precisam apenas resgatar como lidavam com sua casa; outros precisam construir uma maneira de morar, seja com auxílio mais intenso da equipe, seja compondo uma rede que acione outros dispositivos de cuidado, como contratar uma diarista. Não esperamos que as pessoas que estejam no SRT realizem todas suas necessidades sozinhas, afinal, o SRT é um espaço de cuidado e como tal deve incluir uma escuta daquilo que o usuário pode "dar conta" sozinho e de quando precisa ser apoiado mais de perto em seu processo de transição para outro habitar. Trata-se, nesta medida, de uma transição que não começa nem se encerra com a mudança para uma casa.

Como relatado anteriormente, participavam das atividades de transição aqueles que, tomando conhecimento dos objetivos que colocavam os residentes/ pesquisadores naquela equipe, procuravam se aproximar. Contudo, participaram apenas os que receberam aval da equipe de sua unidade no hospital. Nem sempre 
as negociações entre nós ("equipe de transição") e equipes das unidades do hospital foram tranquilas. Os usuários tiveram que lidar, de alguma forma, com as mais diversas implicações que os cuidadores aos quais eram vinculados tinham com os processos de desinstitucionalização e com a própria Reforma Psiquiátrica. Alguns os incentivavam e outros reforçavam suas resistências e temores. Assim, tanto usuários quanto nós mesmos tínhamos que lidar com diferentes desejos intervenientes no nada linear processo de elaboração de uma escolha que mudaria radicalmente os destinos daquelas vidas.

Frente à saída de moradores, percebemos a sensação de perda ${ }^{7}$ nas unidades do hospital. Muitos trabalhadores sentiam a proposta de alta daqueles asilados como se estivessem lhes roubando um morador que, geralmente, é aquele que retribui carinho, que se comunica bem e participa intensamente das atividades propostas, além de auxiliar nas rotinas de banho, almoço, roupas... O desejo muitas vezes manifesto pelos funcionários é de que o morador preferisse ficar no hospital. Percebemos que o morador, não raro, se sente na obrigação de responder a este desejo e não contrariar (abandonar) aquele que sempre cuidou dele baseado numa lógica tutelar. O convite para mudar-se para o Morada está sujeito a produzir o mesmo efeito: o morador pode se sentir obrigado a aceitá-lo como forma de recompensar os cuidadores que o estão incentivando à mudança. Procuramos, através do acompanhamento terapêutico, estreitar vínculos e emprestar o nosso desejo de que fossem para o Morada sem estabelecer uma ação coercitiva. Procuramos criar acontecimentos que convocassem os usuários a outros territórios de vida. A vinheta acima narrada refere-se a um desses acontecimentos: a experimentação de um pernoite em uma casa fora do hospital.

Houve queixas, relacionadas ao sentimento de perda dos funcionários, com argumentos de que apenas os usuários "mais inteiros" eram trabalhados. Essa condição, de alguma forma, foi imposta pelo fato de o Morada se caracterizar como SRT do "tipo I". Mesmo assim, trabalhamos na transição com alguns moradores do HPSP que careceriam de um SRT do "tipo II" para efetivar sua alta hospitalar, o que leva a salientar a importância de estruturação de serviços com cuidados intensivos durante 24 horas ao dia, para efetiva concretização dos objetivos da Reforma Psiquiátrica. Cabe apontar que, também nos SRTs de "tipo II", a busca de ampliação da autonomia e de transição para cidade são objetivos primordiais. Por este motivo, não nos alinhamos à lógica apresentada por Furtado (2006, p. 
791), de que os "residenciais terapêuticos de tipo II seriam necessários somente às experiências mais desenvolvidas que já retiraram os usuários mais autônomos".

Outra importante especificidade que marca este trabalho se deve ao fato de o Morada estar localizado no interior de uma comunidade violenta e empobrecida. Tal circunstância despertou insegurança em profissionais e usuários e, diversas vezes, foi utilizado como principal argumento contrário para o trabalho de transição ou efetivação de mudança para o Morada. O trabalho de transição levou em conta esta situação e procurou, em função dela, potencializar recursos de defesa dos usuários. Trancar as portas de casa, cuidar de seu dinheiro, administrar discussóes com vizinhos foram algumas das aprendizagens com que os novos moradores tiveram que lidar. A perspectiva era sempre a de que tais questôes fazem parte do habitar uma cidade, não importa o local onde esteja sua casa. Neste sentido, a violência urbana constituiu outro dispositivo analisador, pois se tornou tema constante do acompanhamento e mesmo dos Planos Terapêuticos dos moradores.

Consideramos, ainda, que a insegurança é permeada pela lógica tutelar que impõe ao usuário de saúde mental uma condição de perigoso (para si e para os outros). Observamos que os usuários, com diferentes graus de dificuldade, vale ressaltar, puderam trabalhar este argumento, quando se defendiam, por exemplo, da comunidade violenta que os avizinha, mostrando que o perigo não está necessariamente ao lado de quem sofreu uma internação.

O processo de saída do hospital psiquiátrico acarreta ganhos, mas também algumas perdas. Optar entre o olhar vigilante do cuidado tutelar do hospital e o cuidado para a autonomia promovido num SRT como o Morada não é simples, e este é um processo que assume especial visibilidade na ambivalência com que alguns usuários vivem seu processo de transição.

Inês é uma moradora que participa da Casa de Passagem no Morada desde sua inauguração. Ela é a moradora que demonstra maior ambivalência do desejo, ora querendo ir para o Morada, ora querendo permanecer no hospital. Inês coloca-se algumas vezes em uma condição de impotência: "não enxergo direito, estou me sentindo tonta, não lembro como cozinhar". Certo dia, havíamos marcado com Inês e mais uma moradora, um pernoite no Morada. Quando procuramos por Inês no dia marcado, ela não estava na sua unidade do hospital. Levamos algum tempo para localizá-la e, quando conseguimos, ela, brava, afirmou que havia desistido. Respeitamos a decisão e seguimos o combinado com a outra moradora. Na semana 
seguinte, Inês chega correndo ao local do hospital onde estávamos e diz: "Vi vocês passando e vim correndo atrás, achei que não ia alcançar vocês". Em seguida questiona sobre o Morada e como havia a outra moradora passado aquela noite.

Alguns moradores do hospital recusaram os repetidos convites feitos para participarem das atividades de transição. Os já participantes também frequentemente vivenciavam uma ambivalência muito forte entre o contexto hospitalar incorporado e a oferta de um novo território de vida pelo Morada. No artigo em que abordam a recusa de alguns moradores à desospitalização, Machado, Manço e Santos (2005, p. 1475) afirmam que "tendo passado muitos anos internados no hospital, esses pacientes acabam por adaptar-se à patologia hospitalar, a qual lhes retira os meios de governar-se fora dos muros do asilo". Furtado (2001, p. 46) utiliza o termo pacientes cronificados para se referir àqueles que há anos moram em hospital psiquiátrico e que, "como seria de esperar, apresentam demandas e comportamentos institucionalizados, assimilados ao longo de décadas de internação e de disciplina asilar”.

O hospital psiquiátrico, enquanto instituição total (GOFFMAN, 1974), assume a gerência das mais diversas dimensóes da vida do morador, o que, de alguma forma, o leva a incorporar ao longo dos anos dada posição característica desse contexto institucional: uma posição dependente de uma única instituição que totaliza a gerência de todas as dimensões de vida. A gerência, neste caso, é desenvolvida de forma massificada e restritiva. A incorporação das amarras institucionais totalizantes torna a desinstitucionalização mais difícil. Entendemos ser preciso, como já dito, que não se aborte simplesmente o usuário do ambiente institucional, mas permita que ele possa ser investido por outros discursos, vislumbre outras formas de organizar seu viver e visualize uma rede que ofereça proteção para ele fora do hospital. Sair do hospital é enfrentar os medos e as inseguranças gerados pelo desconhecido, mas também aqueles gerados pelo rompimento dessa amarra de segurança institucional.

A ambivalência, fortemente inscrita nesses processos de transição, deve ser incluída como dispositivo analisador para que, desta forma, possibilite o fortalecimento de uma escolha, não sua fragilização. A falta de convicção - em fazer ou não a mudança, em que momento e de que jeito - não foi, em qualquer momento, fator excludente nas atividades que este processo de pesquisa-intervenção propôs. De fato, as atividades desenvolvidas propiciaram a apropriação de novos territórios 
de vida (circulação por outros espaços sociais; aquisição de bens pessoais...).

Oferecemos oportunidades de experimentação, de ir e vir, de estar em ambos os lugares, de que se construísse uma diferenciação desses, contribuindo para que a escolha estivesse a serviço do processo do desejo. Este, vale lembrar, nunca é linear, mesmo em mudanças mais prosaicas de nosso cotidiano. Como esperar que o seja, justo quando se trata de uma transição tão radical?

Entendendo que subjetividade é o processo de produção de si, vimos que o possível para Inês, até então, foi protagonizar uma posição de "entre-tempo" onde, por um lado, se afetava pelas novas possibilidades de viver e, por outro, permanecia respondendo ao modo de subjetivação construído em anos de manicômio. Isto nos levou a respeitar sua decisão de desistir do que havíamos programado conjuntamente para ela, ainda que nossa implicação com a instituição manicomial desejasse todo o tempo "desejar por ela" esta saída. Nossa análise constante desta implicação impediu-nos de usar uma voz de poder do tipo: "nós combinamos e agora você precisa ir".

O trabalho de transição sempre esteve marcado pela característica de ser uma aposta. Uma aposta de que o desejo do usuário de habitar o Morada viesse a se sobrepor. Uma aposta em tempos individuais na apropriação de territórios subjetivos. São tempos desvinculados do preestabelecimento de prazos e modos de ser. Apostávamos que Inês elaborava um desejo de se mudar e que sua desistência naquele momento não significava algo definitivo, mas parte importante de seu processo de experimentação da mudança.

O respeito ao tempo e aos medos de Inês não significou não insistir; afinal, a própria Inês insiste e volta a procurar, dizendo: "quase não alcancei vocês". Demonstrou o receio de ter magoado nosso desejo de que mudasse, de ter sido abandonada no seu processo ou punida pela sua ambivalência. A transição envolve outras formas de subjetivação que para Inês estavam sendo muito difíceis de lidar. Durante as atividades de AT que realizamos, obtivemos diferentes respostas que anunciavam os tempos individuais dos usuários: alguns ansiosos por deixarem o hospital, outros que desistiram do processo de transição, outros, ainda, que permaneceram ambivalentes.

Sentada certo dia no sofá de sua casa, Ana fala dos beneficios de estar morando em um serviço residencial e não mais na unidade do hospital: "agora eu tenho minha casa, meu quarto, não preciso mais ficar com as gurias, mas a gente continua sendo amigas". 

Pedro, chegou ao Morada onde passariam a noite na Casa de Passagem. Ana era da mesma unidade de Amélia antes de mudar-se para o Morada. Ao ver o casal na rua, começou a esbravejar, dizendo: "agora eu tenho a minha casa, ninguém mais manda em mim, quem manda em mim sou eu”. Repetiu estas frases diversas vezes em alto tom de voz, caminhando de um lado para o outro próximo de onde estavam Amélia e Jorge.

Refletindo sobre os dois momentos de Ana, podemos identificar como central o conflito massificação versus singularização. Cogitamos que a presença de Amélia trouxe a Ana associações com a unidade onde dividia o quarto com muitas outras mulheres. Ana, naquele momento, deixava aflorar uma agressividade que se contrapunha à passividade estimulada/disciplinada no hospital psiquiátrico. Aflorava uma afirmação de um espaço que era seu, aflorava um desejo de mandar em si, de tomar decisões, de concretizar desejos, de ter voz. E grita: "Agora quem manda em mim sou eu”. E grita: "Agora eu tenho uma casa". Uma casa que é sua, onde há espaços de negociação diferentes para o seu "sair da casa". Onde ela coabita e se autoriza a afirmar "ninguém mais manda em mim" subvertendo a disciplina das instituições totalizantes antes habitadas. Ana, ao afirmar-se como "dona" de um espaço, defendendo-o, marca seu desejo pelo privado e pela apropriação de um território outro. Estar no residencial permite a Ana perceber uma relação que difere do estabelecido no hospital psiquiátrico onde se submetia às rotinas da unidade ditadas por outros "donos". Também no SRT existem rotinas a serem desenvolvidas, mas há uma relação equipe/usuário de singularização que potencializa, através de um plano terapêutico individualizado, a construção das decisões e uma apropriação das mesmas pelas duas partes envolvidas. É essa diferente relação que oferece a possibilidade para que Ana sustente a condição de "dona” de um espaço.

A singularização do cuidado aparece como ponto central na Reforma Psiquiátrica. Ocorre uma passagem de um cuidado massificado calçado na crença das generalizaçóes biomédicas para um cuidado baseado na multiplicidade e na complexidade enquanto características do viver da humanidade.

Ana anuncia a diferenciação entre o espaço hospitalar massificado, comum a todos - onde não pode optar em conviver ou não com alguém - e a apropriação do seu espaço singular. Consegue ter clareza da diferença de ter um vínculo com o hospital e ter relaçóes de amizade com as pessoas com as quais conviveu por 
mais de 20 anos. Sua decisão por habitar o espaço do Morada e reconhecer os benefícios que isto lhe trouxe não a impede de manter as amizades. Elabora a importância de seu espaço privado e procura suas amigas quando sente saudade.

\section{Transitar sempre...}

Vivemos durante a pesquisa um trabalho que se volta para o desejo dos atores sociais envolvidos. O desejo dos usuários que é resgatado e potencializado, o desejo de uma equipe que luta constantemente para ampliar seus territórios de intervenção e o desejo dos pesquisadores de contribuir no processo de desinstitucionalização através de um trabalho de reflexão e mudança. Todos caminhando em direção a construir territórios subjetivos que produzam diferenças, trazendo à tona a marca da singularidade.

Recortes de vida como os expostos acima permitem entender a transição não apenas como uma mudança de um espaço físico para outro, mas como uma apropriação de novos territórios, de espaços da cidade, e como uma ressignificação da posição subjetiva dos sujeitos-moradores. Dentro dessa lógica, a transição extrapola o processo de mudança do HPSP para o Morada e acaba se constituindo como a principal função de um SRT. Afinal a transição não é para o Morada e, sim, para a cidade, para outros territórios. Novas formas de viver e ver a vida. $\mathrm{O}$ próprio Morada não pode ser visto como a parada final de um itinerário. Para alguns moradores, o SRT até se constitui como a casa definitiva a habitar. Mesmo nesse caso, o SRT deve agir de forma a agenciar ampliação desses territórios de vida e abalar o manicômio incorporado. Agenciar as multiplicidades da cidade é estar atento para não institucionalização dos moradores dentro do SRT. Para outros moradores, o SRT pode ser um lugar de passagem para outras casas da cidade, inclusive em outros municípios.

Entre os resultados desta pesquisa temos a reativação do processo de altas para o SRT que se encontrava parado, a destinação da estrutura de um SRT para realização de atividades de transição e a continuidade do trabalho de acompanhamento da transição de moradores do hospital por trabalhadores da equipe do Morada. É importante assinalar que, na fase turbulenta em que se iniciou este trabalho com demandas constantes e recursos escassos, a diretriz da equipe era direta: "ninguém mais muda”. A tranquilização do cenário político e nossa constante interação com a equipe do Morada contribuiu para que a 
mudança de novos usuários não fosse vista apenas como sobrecarga de trabalho, mas como novas conquistas do serviço.

Consideramos que circular pela cidade, relacionar-se com outras pessoas, apropriar-se de novos lugares que produzam sentido, realizar escolhas a partir de desejos mutantes, enfim, afetar-se por novos processos de subjetivação são ações que potencializam os processos de desinstitucionalização da loucura e, com eles, os objetivos da Reforma Psiquiátrica.

O acompanhamento terapêutico voltado para a transição convocou afetos em moradores e proporcionou dispositivos analisadores a nós pesquisadores, mas também afetou pessoas e instituições que nos atravessam o tempo todo e parecem se exacerbar durante o experimento de "transitar". Entre eles, encontra-se o shopping center, com seus imponentes seguranças que definem quem pode ou não nele circular; os ônibus, com seus distraídos passageiros que não gostam de ser perturbados com presenças inusitadas; os transeuntes normatizados, que não lidam cotidianamente com a diferença radical que a loucura lhes impõe. Mesmo funcionários do hospital contrários ao processo de mudança tiveram que lidar com o fato de que seus pacientes passaram noites sozinhos no Morada e sozinhos sobreviveram. Depois fins de semana, depois mudança. E agora vivem em outros territórios.

A criação de um serviço substitutivo ao manicômio, no caso o Morada, não garante por si mesmo que o aparato manicomial seja superado. A superação consiste em romper os paradigmas que fundamentam e autorizam a instituição psiquiátrica clássica e seus paradigmas clínico e racionalista de causa e efeito. $\mathrm{O}$ que fica claro com o desenvolvimento da pesquisa é que o processo de transição é tomado pelo Morada como seu grande desafio. O desafio de potencializar a transição de moradores de um espaço manicomial para outro habitar, ao criar e consolidar novos paradigmas de cuidado. Paradigmas contrários à lógica tutelar do manicômio, contrários a todo aparato manicomial que segue pregando como "modelo terapêutico" a incapacidade dos portadores de sofrimento psíquico, seu imobilismo e a consequente condenação à clausura.

O cuidado emancipatório pode ser visualizado no trabalho de transição através do respeito aos tempos dos usuários, do cuidado com a ambivalência, do resgate da potência em uma voz que anuncia escolhas. O protagonismo na própria vida é a marca desinstitucionalizante proporcionada pelo transitar por novos territórios. 
São territórios que propiciam novos agenciamentos e a composição de redes de vida. A clínica da Reforma Psiquiátrica entende a circulação como possibilidade de experimentação de outros territórios de cuidado, nos quais a pessoa se coloca como desejante e se serve dos encontros com o inusitado para produções de si.

Neste sentido, o "trânsito" perde seu caráter de um meio, mera etapa de uma forma de vida pressuposta, para assumir uma conotação de um fim maior. "Transitar", como um movimento que favorece a vida, pode então ser compreendido como uma finalidade em si. No contraponto do cuidado que imobiliza, "faz-morrer", temos o cuidado que potencializa o movimento "fazviver”. E a vida, vale lembrar, não é estagnação, senão produção do novo.

\section{Referências}

BERGER, E. et al. Introdução a clínica do acompanhamento terapêutico. In: A CASA. Equipe de acompanhantes terapêuticos do hospital dia. A rua como espaço clínico: acompanhamento terapêutico. São Paulo: Escuta, 1991.

BRASIL. Ministério da Saúde. Secretaria de Atenção à Saúde. Departamento de Ações Programáticas Estratégicas. Coordenação de Saúde Mental. Saúde Mental em dados, v. 1, n. 3, 2006.

BRASIL. Ministério da Saúde. Secretaria-Executiva. Secretaria de Atenção à Saúde. Legislação em saúde mental: 1990-2004. Brasília: Ministério da Saúde, 2004.

BRASIL. Ministério da Saúde. Secretaria-Executiva. Secretaria de Atenção à Saúde. Residências terapêuticas: o que são, para que servem. Brasília: Ministério da Saúde, 2004.

BRASIL. Ministério da Saúde. Manual do Programa "De Volta Para Casa". Brasília: Ministério da Saúde, 2003.

CABRAL, K.V.; BELLOC, M.M. O acompanhamento terapêutico como dispositivo da Reforma Psiquiátrica: duas experiências em saúde mental coletiva. In: PALOMBINI, A.L. et al. Acompanhamento terapêutico na rede pública: a clínica em movimento. Porto Alegre: UFRGS, 2004. p. 113-124.

CABRAL, K.V. Algumas asserçōes sobre a identidade do acompanhante terapêutico. In: PELLICIOLI, E. et al. Cadernos de AT: uma clínica itinerante. Porto Alegre: 1998.

FIORATI, R.C. Acompanhamento terapêutico: uma estratégia terapêutica em uma unidade de internação psiquiátrica. Dissertação (Mestrado). Escola de Enfermagem de Ribeirão Preto, Universidade de São Paulo, 2006.

FURTADO, J.P. Avaliação da situação atual dos Serviços Residenciais Terapêuticos no SUS. Ciência \& Saúde Coletiva, v. 11, n. 3, p. 785-795, 2006. 
FURTADO, J.P. Responsabilização e vínculo no tratamento de pacientes cronificados: da unidade de reabilitação de moradores ao CAPS Estação. In: HARARI, A.; VALENTINI, W. (Org.). A reforma psiquiátrica no cotidiano. São Paulo: Hucitec, 2001.

GOFFMAN, Erving. Manicômios, prisóes e conventos. São Paulo: Perspectiva, 1974.

JARDIM, C.; WACHS, F.; GOMES, R.C.M. A história de uma travessia. Disponível em: <http://www.topia.com.ar/articulos/405-madres-6.htm>. Acesso em: 25 nov. 2005.

MACHADO, V.; MANÇO, A.R.X.; SANTOS, M.A. A recusa à desospitalização psiquiátrica: um estudo qualitativo. Cadernos de Saúde Pública, Rio de Janeiro, v. 21, n. 5, p. 1472-1479, 2005.

PALOMBINI, A. Acompanhamento terapêutico na rede pública: a clínica em movimento. Porto Alegre: Editora da UFRGS, 2004.

PASSOS, E.; BARROS, R.B. A construção do plano da clínica e o conceito de transdisciplinaridade. Revista de Psicologia: teoria e pesquisa, v. 16, n. 1, p. 71-79, 2000.

PAULON, S.M. et al. Das múltiplas formas de habitar uma morada. A produção do cuidado em um serviço residencial terapêutico. Revista Vivência, Natal, n. 32, p. 119-137, 2007.

PAULON, S.M. A análise de implicação como ferramenta na pesquisa-intervenção. Psicologia e Sociedade, v. 17, n. 3, p. 18-25, 2005.

PITIÁ, A.C.A. Acompanhamento terapêutico sob o enfoque da psicoterapia corporal: uma clínica em construção. Tese (Doutorado). Escola de Enfermagem de Ribeirão Preto, Universidade de São Paulo, Ribeirão Preto, 2002.

ROCHA, M.L.; AGUIAR, K.F. Pesquisa-intervenção e a produção de novas análises. Psicologia Ciência e Profissão, v. 23, n. 4, p. 64-73, 2003.

ROTELLI, F. et al. Desinstitucionalização. São Paulo: Hucitec, 1990.

TENÓRIO, F. A psicanálise e a clínica da reforma psiquiátrica. Rio de Janeiro: Rios Ambiciosos, 2001.

\section{Notas}

1 "O Serviço Residencial Terapêutico (SRT) são casas localizadas no espaço urbano, constituídas para responder às necessidades de moradia de pessoas portadoras de transtornos mentais graves, institucionalizadas ou não" (BRASIL, 2004b, p. 6).

2 "Desinstitucionalização é um trabalho prático de transformação que, a começar do manicômio, desmonta a solução institucional existente para desmontar (e remontar) o problema. Concretamente, se transformam os modos nos quais as pessoas são tratadas (ou não tratadas) para transformar o seu sofrimento, porque a terapia não é mais entendida como a perseguição da solução-cura, mas como um conjunto complexo, e também cotidiano e elementar, de estratégias indiretas e mediatas que enfrentam o problema em questão através de um percurso crítico sobre os modos de ser do próprio tratamento. O que é, portanto, nesse sentido "a instituição" nessa nova acepção? É o conjunto de 
aparatos científicos, legislativos, administrativos de códigos de referência e de relação de poder que se estruturam em torno da "doença". Mas se o objeto, ao invés de ser a "doença", torna-se "a existênciasofrimento do paciente" e a sua relação com o corpo social, então desinstitucionalização será o processo crítico-prático para reorientação de todos os elementos construtivos da instituição para este objeto bastante diferente do anterior" (ROTELLI, 1990, p. 29).

${ }^{3} \mathrm{O}$ artigo foi elaborado tendo por base o trabalho de conclusão da Residência Integrada em Saúde com Ênfase em Saúde Mental Coletiva, da Escola de Saúde Pública do RS, intitulado Serviços Residenciais Terapêuticos Morada São Pedro: processos de subjetivação e territórios de vida, de autoria de Camila Jardim e Felipe Wachs, e contou com orientação de Simone Paulon e Vera Resende.

${ }^{4}$ O projeto foi submetido ao Comitê de Ética em Pesquisa do Hospital Psiquiátrico São Pedro da Secretaria da Saúde e Meio Ambiente do Estado do Rio Grande do Sul e aprovado sob o número 05010.

5 "A noção de território vai além de uma regionalização administrativa: o território não é (apenas) o bairro de domicílio do sujeito, mas o conjunto de referências socioculturais e econômicas que desenham a moldura do seu cotidiano, de seu projeto de vida, de sua inserção no mundo" (TENÓRIO, 2001, p. 71).

${ }^{6}$ Ver mais desta abordagem em Berger (1991), Cabral (1998), Pitiá (2002), Palombini (2004) e Fiorati (2006).

${ }^{7}$ Paulon et al. (2007) descrevem a mesma percepção sobre a reação de perda por parte de funcionários do Hospital Psiquiátrico São Pedro. Furtado (2001, p. 39) relata experiência semelhante no Serviço de Saúde Dr. Cândido Ferreira, em Campinas, em que a desospitalização de moradores trouxe ao cotidiano "fantasias de morte, de perda do emprego e incertezas quanto ao futuro [...]". Furtado (2006) afirma que o raciocínio de perda de emprego não se justifica, pois constatou que com a criação de SRTs, ao contrário dessa expectativa, o número de postos de trabalho em saúde mental aumenta. 


\section{Abstract}

Subjective processes and life territories: the transition from the psychiatric hospital to therapeutic residential services

The paper discusses mental health care in the context of Psychiatric Reform being implemented in Brazil. It is the results of a research-intervention proposal that potentializes deinstitutionalization of residents of São Pedro Psychiatric Hospital, and addresses more specifically the transition work therapeutic residential services Morada São Pedro, in Porto Alegre city, Brazil. Beyond the mere displacement of a physical space to another, this transition concept relates more to the subjective appropriation of new subjective territories and other forms of life and living. The subjectivation processes emerging among users, workers and researchers, when moving into new life territories, were used as analyzing devices and are problematized here, in order to think over the role transition would play in the life production of these new members of urban life.

> Key words: mental health; mental health services; deinstitutionalization; subjective process. 